\title{
长江中游城市群创新平台空间分布 及其影响因素分析
}

\author{
唐承丽 ${ }^{1}$, 郭夏爽 ${ }^{1}$, 周国华 ${ }^{1,2}$, 吴佳敏 ${ }^{1}$, 陈伟杨 ${ }^{1}$ \\ (1. 湖南师范大学资源与环境科学学院, 长沙 410081 ; \\ 2. 湖南师范大学地理空间大数据挖掘与应用湖南省重点实验室,长沙 410081)
}

\begin{abstract}
摘 要: 创新是引领发展的第一动力。创新平台作为区域创新体系的重要组成部分和集聚创新资源的核心支撑载体, 是推动创新驱动发展的主要抓手。论文以长江中游城市群为研究区域, 运用最邻近指数、核密度估计、Ripley's $K$ 函数、地理探测器等方法, 探究 2017年长江中游城市群省级以上创新平台的空间分布特征及其影响因素。结果表明: (1) 长江中游城市群创新平台整体呈现出集聚分布特征, 以武汉、长沙和南昌为核心呈“品字形”的分布格局; (2) 基 于不同等级和不同功能类型划分的各类创新平台均呈现出显著集聚的特征, 但集聚强度和集聚状态存在一定差 异; (3) 创新平台总体和不同类型创新平台的空间集聚存在尺度效应,随地理距离的变化空间集聚趋势先增强后减 弱; (4) 创新平台的空间分异是多因素综合作用的结果, 金融实力、信息化程度、利用外资水平、人力资本条件的影 响最为显著,其次为交通可达性、城镇化水平、经济基础和创新氛围。
\end{abstract}

关 键 词: 创新平台; 空间分布; 长江中游城市群

随着知识经济和信息时代的到来,创新已成为 经济增长的动力源泉, 成为各国、各地区发展生产 力的核心要素。创新平台作为创新活动的主要支 撑载体和创新体系的重要组成部分 ${ }^{[1]}$, 在集聚创新 资源、促进科技成果转化和产业化、拓展创新空间 以及提升区域创新能力等方面起着至关重要的作 用。国家和各级政府积极促进创新平台的建设, 出 台了《国家中长期科学与技术发展规划》《国家创新 驱动发展战略纲要》《“十三五” 国家科技创新规 划》, 提出建设创新型国家与创新型省份等相关政 策与战略 ${ }^{22}$, 但平台目前也存在着过度追求数量、发 展参差不齐、基础设施配套不完善等问题。因此, 如 何合理建设创新平台、优化创新空间布局, 已成为当 下亟待解决的战略性问题。创新平台的概念最早可 追溯到美国竞争力委员会《走向全球: 美国创新新形
势》的研究报告中, 其认为创新平台主要包括创新基 础设施和创新过程中不可缺少的各类要素 ${ }^{[3]}$ 。当前 学术界基于地理学、管理学、经济学和生态学等学科 视角, 综合运用问卷调查、数据包络分析、多因素综 合评价、空间计量模型等方法, 主要围绕创新平台的

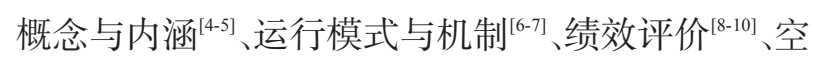

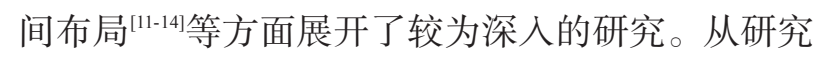
对象来看, 多集中在将创新平台视为一个整体进行 整合研究或单独针对某类平台展开分析 ${ }^{[15-16]}$, 少有研 究将创新平台总体和各类创新平台进行比较研究。 从研究内容来看, 多是对创新平台的功能定位和发 展模式进行定性分析以及基于企业投资、专利申请 等统计数据进行创新空间演化规律的探究 ${ }^{[17-20}$, 运用 位置数据探究平台的区域差异和空间关系并不多 见。从研究尺度和地域来看, 大多以全国、省域、城

收稿日期: 2019-09-11; 修订日期: 2019-12-16。

基金项目: 国家自然科学基金项目(41371144); 湖南省科技创新决策咨询暨软科学重点项目(2018ZK3007)。 [Foundation: National Natural Science Foundation of China, No. 41371144; Science and Technology Innovation Decision-Making Consultation and Soft Science Key Projects of Hunan Province, No. 2018ZK3007. ]

第一作者简介:唐承丽(1964-), 女, 湖南汶阳人,教授,博士生导师,主要从事区域经济与开发区发展研究。

E-mail: tclxy68@163.com

引用格式: 唐承丽, 郭夏爽, 周国华, 等. 长江中游城市群创新平台空间分布及其影响因素分析 [J]. 地理科学进展, 2020, 39(4): 531-541. [Tang Chengli, Guo Xiashuang, Zhou Guohua, et al. Spatial distribution and influencing factors of innovation platforms in urban agglomerations of the middle reaches of the Yangtze River Basin. Progress in Geography, 2020, 39(4): 531-541. ] DOI: 10.18306/dlkxjz.2020.04.001 
市和东部发达地区为主, 如: 孙庆 ${ }^{[21]}$ 结合国内外创 新平台建设实际情况, 认为其空间分布模式主要包 括均衡布局、点极布局和点轴布局 3 种模式; 王雪原 等 ${ }^{[22]}$ 基于区域各主体实力、产业发展情况、经济科技 发展水平以及创新服务需求等方面提出了创新平 台四维度布局优化方法; 丛海涁等 ${ }^{[23]}$ 探究了浙江省 创新平台空间分布特征, 结果表明该省平台存在显 著集聚分布特征; 滕堂伟等 ${ }^{[2]}$ 分析了长三角地区众 创空间的空间格局演变特征, 认为其三核多中心的 空间集聚形态将日渐显著; 唐凯等 ${ }^{[25]}$ 研究发现南京 市众创空间整体呈现两心一带多点的空间分布特 征, 布局驱动力由单一转向多元。但针对城市群地 区和中西部地区创新平台空间分布的探究相对来 说比较少。

城市群作为社会经济发展的重心、产业集聚的 空间和科技文化的中心 ${ }^{[26]}$, 创新平台数量多、水平 高。同时, 创新平台的搭建有助于城市群中各城市 对产业进行合理的布局, 培育出具备竞争力的顶尖 企业, 提升城市群的核心竞争力。长江中游城市群 是以武汉城市圈、环长株潭城市群、环鄱阳湖城市 群为主体形成的特大型城市群, 不仅支撑着长江经 济带的发展, 而且也是中部地区崛起的核心区域以 及中国经济增长的重要引擎 ${ }^{[27-28]}$ 。基于此, 本文运 用最邻近指数、核密度估计、Ripley's $K$ 函数、地理探 测器等方法, 对 2017 年长江中游城市群省级以上创 新平台的空间分布特征及其影响因素进行探究, 进 一步厘清长江中游城市群创新平台现状及其空间 分异规律, 为长江中游城市群的创新发展提供相关 理论支持和决策参考, 从而提升长江中游地区的创 新能力, 加速推动中部地区的崛起。

\section{1 研究方法与数据来源}

\section{1 研究方法}

\subsection{1 最邻近指数法}

最邻近指数法(Nearest Neighbor Index Method) 用于确定创新平台的空间分布模式, 其核心内容是 计算出最邻近指数, 最邻近指数是指点要素的实际 最邻近平均距离与随机分布模式下的理想最邻近 平均距离之间的比值 ${ }^{[29]}$ 。计算公式具体如下:

$$
\begin{gathered}
\mathrm{NNI}=\overline{D_{0}} / \overline{D_{E}} \\
\overline{D_{0}}=\sum_{i=1}^{n} \frac{\min \left(d_{i j}\right)}{n}, \quad \overline{D_{E}}=\frac{1}{2} \sqrt{\frac{A}{n}}
\end{gathered}
$$

式中: $\mathrm{NNI}$ 为最邻近指数; $\overline{D_{0}}$ 为创新平台点对之间 的实际最邻近平均距离; $\overline{D_{E}}$ 为随机分布模式下的 理想最邻近平均距离; $i, j$ 分别为空间上任意 2 个创 新平台; $d_{i j}$ 为 2 个创新平台之间的实际距离; $A$ 为长 江中游城市群面积; $n$ 为创新平台数量。

\subsection{2 核密度估计}

核密度估计法(Kernel Density Estimation)用于 识别创新平台的空间集聚区域。其原理是测算出 点要素在其周围邻域中的密度,清晰反映其在空间 上的集聚或分散特征 ${ }^{[30]}$ 。计算公式具体如下:

$$
f(x)=\frac{1}{n h} \sum_{i=1}^{n} K\left(\frac{x-x_{i}}{h}\right)
$$

式中: $f(x)$ 表示创新平台的核密度估计值; $n$ 表示创 新平台数量; $h$ 表示带宽, 即圆域的半径; $K$ 函数表 示空间权重函数; $x-x_{i}$ 表示 2 个创新平台之间的估 计距离。

\subsubsection{Ripley's $K$ 函数}

Ripley's $K$ 函数用于分析创新平台空间集聚的 尺度特征以及在何种空间特征尺度下,创新平台的 集聚强度和集聚规模达到最大 ${ }^{[31]}$ 。计算公式如下:

$$
\begin{gathered}
K(d)=A \sum_{i=1}^{n} \sum_{j=1}^{n} \frac{w_{i j}(d)}{n^{2}} \\
L(d)=\sqrt{\frac{K(d)}{\pi}}-d
\end{gathered}
$$

式中: $K(d)$ 表示 $K$ 函数; $A$ 表示研究区面积; $n$ 表示创 新平台数量; $d$ 表示距离尺度; $w_{i j}(d)$ 表示在距离 $d$ 范 围内创新平台 $i, j$ 之间的距离; $L(d)$ 是 $\operatorname{Besag}^{[32]}$ 提出 的用于取代 $K(d)$ 并对 $K(d)$ 作开方线性变换、以保持 方差稳定的函数。

\subsection{4 地理探测器}

地理探测器(Geo-detector)用于探究创新平台 空间分异的影响因素。其中探测 $Y$ 的空间分异性以 及某影响因素 $X$ 多大程度上解释了 $Y$ 的空间分异, 用 $q$ 值来度量 ${ }^{[33]}$ 。其表达式为:

$$
q=1-\frac{1}{n \sigma^{2}} \sum_{h=1}^{L} n_{h} \sigma_{h}^{2}
$$

式中: $q$ 表示影响因素对创新平台空间分异的决定 力; $n$ 和 $n_{h}$ 分别表示研究区内所有的创新平台数和 类型 $h$ 内的创新平台数; $\sigma^{2}$ 和 $\sigma_{h}^{2}$ 分别表示研究区 内所有创新平台的离散方差和类型 $h$ 内创新平台的 离散方差; $L$ 表示各影响因素的类型数。

\section{2 数据来源}

本文以《长江中游城市群发展规划》的行政范 
围为基础, 同时考虑到数据获取的完整性, 将江西 省抚州市和吉安市整体纳人研究范围,包括湖北、 湖南和江西 3 省的 31 个市级行政单位 ${ }^{(1)}$ 。综合目前 已有的研究, 并结合长江中游城市群创新平台的发 展实际, 本文认为创新平台是以高校、科研院所和 企业等为主要依托主体, 可为研究、开发、应用等创 新活动提供各类创新资源 (如人力、物力、财力和信 息资源等)的空间载体, 依据国家科技部及湖北、湖 南、江西 3 省科技厅等政府部门对于创新平台的界 定, 同时考虑平台的规模性和数据的可得性, 选取 省级以上众创空间、科技企业捊化器、重点实验室、 工程技术研究中心、企业技术中心、星创天地、国际 科技合作基地以及高新技术产业开发区(园区) 8 类 创新平台作为研究对象。2017年, 长江中游城市群 创新平台共 3352 个。依据创新平台的等级, 可将长 江中游城市群创新平台分为国家级创新平台和省 级创新平台, 数量分别为 570 个和 2782 个。依据孙 庆等 ${ }^{[1]} 、$ 古志文等 ${ }^{[34]}$ 的研究, 可将长江中游城市群按 照功能类型分为 3 类: 以开展基础研究为主的知识 型创新平台, 包括重点实验室、工程技术研究中心 和国际科技合作基地; 以发展高新技术产业或创新 型企业为主的产业型创新平台,包括企业技术中心 和高新技术产业开发区(园区); 为创新创业活动提 供综合服务的服务型创新平台, 包括众创空间、科 技企业孵化器和星创天地。3 个类型数量分别为 1522、1048 和 782个。各类型创新平台的具体分布 情况见表 1 。创新平台的名录、组建年份等数据来 源于国家科技部及湖北、湖南、江西三省的科技厅、 发改委等政府部门官方网站。其他数据来源于《中 国城市统计年鉴》《湖北统计年鉴》《湖南统计年鉴》
《江西统计年鉴》(2018 年)以及各市《国民经济和社 会发展统计公报》(2017年)。

\section{2 长江中游城市群创新平台空间格局 特征}

\section{1 长江中游城市群创新平台总体空间分布形态}

通过腾讯坐标拾取器获取长江中游城市群创 新平台的空间经纬度坐标, 借助 ArcGIS 软件进行 空间匹配,运用自然断裂法进行聚类分析,如图 1 所 示。依据 2017 年长江中游城市群创新平台的空间 分布情况可知,城市群创新平台总体呈现出 “内密 外疏”的空间分布形态,大多集中在各城市内部区 域,外侧区域则零星分散着少数创新平台。具体来 看, 创新平台在长江中游城市群的 31 个城市中均有 分布,但各市之间创新平台的分布具有显著的不均 衡性。从子城市群层面来看,武汉城市圈拥有创新 平台最多, 达 1442 个, 环长株潭城市群和环鄱阳湖 城市群的平台数量相差不大, 分别为 962 个和 948 个。从城市层面来看, 各市拥有的创新平台数量差 距显著, 武汉市的创新平台数量最多, 高达 727 个, 天门市的创新平台数量最少, 仅有 11 个; 省会城市 的创新平台数量远超其他城市, 武汉市、长沙市和 南昌市 3 市共分布了 1657 个, 占城市群创新平台总 数的 $49.43 \%$; 拥有 100 个及以上创新平台的城市仅 有 6 个, 依次为武汉市、长沙市、南昌市、宜昌市、襄 阳市和株洲市。

\section{2 长江中游城市群创新平台空间分布模式}

运用最邻近指数探究长江中游城市群创新平台 总体及不同等级、不同功能类型创新平台的空间分

表 1 长江中游城市群创新平台分布情况

Tab.1 Distribution of innovation platforms in urban agglomerations of the middle reaches of the Yangtze River Basin (个)

\begin{tabular}{llrrrr}
\hline \multicolumn{1}{c}{ 名称 } & \multicolumn{1}{c}{ 主要功能 } & 功能类型 & 国家级 & 省级 & 总计 \\
\hline 重点实验室 & 组织基础研究 & 知识型 & 49 & 485 & 534 \\
工程技术研究中心 & 工程应用方面的技术研究 & 知识型 & 39 & 894 & 933 \\
国际科技合作基地 & 发挥国际科技合作 & 知识型 & 55 & - & 55 \\
企业技术中心 & 企业开展自主创新、成果转化 & 产业型 & 103 & 898 & 1001 \\
高新技术产业开发区(园区) & 发展高新技术产业 & 产业型 & 20 & 27 & 47 \\
众创空间 & 提供创业公共服务 & 服务型 & 139 & 249 & 388 \\
科技企业孵化器 & 为高新技术中小企业提供服务 & 服务型 & 78 & 161 & 239 \\
星创天地 & 提供农业科技创新创业服务 & 服务型 & 87 & 68 & 155 \\
总计 & - & - & 570 & 2782 & 3352 \\
\hline
\end{tabular}

(1) 湖北区域包括武汉、黄石、鄂州、黄冈、孝感、咸宁、仙桃、潜江、天门、襄阳、荆州、荆门; 湖南区域包括长沙、株洲、湘潭、岳阳、益阳、常德、衡 阳、娄底; 江西区域包括南昌、九江、景德镇、鹰潭、新余、宜春、萍乡、上饶、抚州、吉安。 


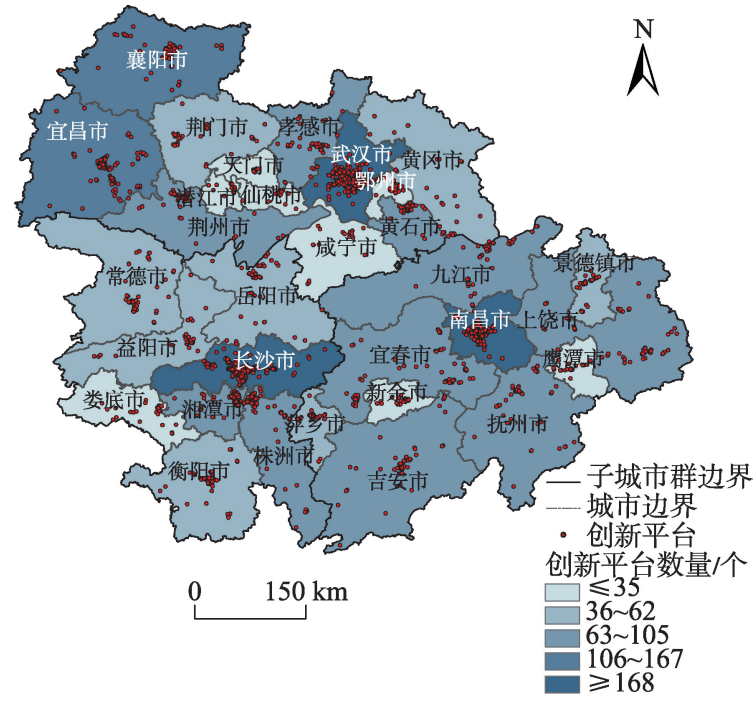

图 1 长江中游城市群创新平台总体空间分布

Fig.1 Overall spatial distribution of innovation platforms in urban agglomerations of the middle reaches of the Yangtze River Basin

布模式,最邻近指数及相关参数的计算结果见表 2 。 结果显示,创新平台总体的实际平均观测距离小于 理论预期平均距离, 最邻近指数为 0.2009 , 远小于 $1, Z$ 检验值小于临界值 $-2.58, P$ 值 $<0.0001$, 表明在 0.01 的水平下通过显著性检验, 由此可判断城市群 创新平台总体呈现出显著集聚的特征。从不同等 级来看, 国家级和省级创新平台的最邻近指数均小 于 1 ,且通过 0.01 的显著性检验, 呈现出显著集聚的 状态, 其中国家级创新平台的最邻近指数高于省级 创新平台, 说明省级创新平台的空间集聚程度比国 家级创新平台更为显著, 国家级创新平台的分布相 对较为均衡。从不同功能类型来看, 知识型、产业 型和服务型创新平台的最邻近指数分别为 0.2441 、 0.3040 和 0.3247 , 且在 0.01 的水平下显著, 均呈显著 集聚特征,集聚程度由大到小依次是知识型创新平 台、产业型创新平台和服务型创新平台。由此可
见，创新平台总体以及不同类型创新平台在空间上 均呈显著集聚的分布模式,但集聚程度具有一定的 差异。

\section{3 长江中游城市群创新平台空间分布集聚特征}

运用核密度估计法进一步识别长江中游城市 群创新平台总体及不同等级、不同功能类型创新平 台的空间集聚区域,核密度分布情况如图 2 所示。 创新平台总体空间分布呈现出 3 个集聚核心, 即以 武汉、长沙和南昌为核心呈 “品字形”分布状态, 与 子城市群中心城市分布状态相吻合,密度总体呈现 出由核心城市向周边地区递减的特征,武汉、长沙 和南昌的创新平台空间分布密度最高, 集聚特征最 明显,其中, 集聚程度由大到小依次是武汉、长沙和 南昌。国家级和省级创新平台均呈现出“一主两 次”的集聚特征,“一主”为武汉，“两次”为长沙和南 昌,但对比二者的核密度分布图可得,省级创新平台 分布地域较国家级创新平台而言更为广泛,这是由 于国家级创新平台的认定标准较高, 其数量远小于 省级创新平台。就不同功能类别创新平台而言, 知 识型创新平台呈现出“两主一次”的集聚态势, “两 主”为武汉和长沙, “一次”为南昌, 这是由于该平台 主要依托主体为高校、科研院所及重大研发机构, 多集中在省会城市;产业型创新平台呈现出“一主 四次”的分布态势, “一主”为武汉，“四次”为南昌、 长沙、襄阳和宜昌,作为科研成果扩散的关键,产业型 创新平台主要围绕工业城市中心进行分布; 服务型 创新平台呈现出“一主两次”的分布态势, “一主”为 武汉, “两次”为长沙和南昌, 诸如众创空间、星创天 地等属低成本、开放式、便利化的新兴创新平台, 其 空间集聚形态会随着服务对象的变化而产生变化， 但就现状来看, 襄阳和宜昌作为产业型创新平台的 次级集聚中心,其服务平台并未完全匹配上来。

\section{4 长江中游城市群创新平台空间分布尺度特征}

运用 Ripley's $K$ 函数分析长江中游城市群创新

表 2 长江中游城市群创新平台最邻近指数及相关参数

Tab.2 Nearest neighbor index and related parameters of innovation platforms in urban agglomerations of the middle reaches of the Yangtze River Basin

\begin{tabular}{|c|c|c|c|c|c|c|c|}
\hline & 类型 & 平均观测距离/km & 预期平均距离/km & NNI & Z值 & $P$ 值 & 分布模式 \\
\hline \multicolumn{2}{|c|}{ 创新平台总体 } & 1.18 & 5.88 & 0.2009 & -88.5038 & $<0.0001$ & 显著集聚 \\
\hline \multirow[t]{2}{*}{ 按等级 } & 国家级创新平台 & 4.27 & 13.98 & 0.3052 & -31.7333 & $<0.0001$ & 显著集聚 \\
\hline & 省级创新平台 & 1.38 & 6.41 & 0.2155 & -79.1598 & $<0.0001$ & 显著集聚 \\
\hline \multirow[t]{3}{*}{ 按功能类型 } & 知识型创新平台 & 2.00 & 8.20 & 0.2441 & -56.4158 & $<0.0001$ & 显著集聚 \\
\hline & 产业型创新平台 & 3.07 & 10.11 & 0.3040 & -43.1013 & $<0.0001$ & 显著集聚 \\
\hline & 服务型创新平台 & 3.85 & 11.87 & 0.3247 & -36.1253 & $<0.0001$ & 显著集聚 \\
\hline
\end{tabular}


平台总体及不同等级、不同功能类型创新平台多尺 度下的空间分布格局, 计算结果如图 3 所示。创新 平台总体的 $L(d)$ 曲线位于上包络线上方, 表明在 0 $250 \mathrm{~km}$ 之间的空间尺度下, 创新平台总体呈先增长 后下降的倒“U”型显著集聚特征, 即在 0 27.69 km 范围内, 空间集聚性不断增强, 在 $27.69 \mathrm{~km}$ 处集聚
程度达到最大值, 此时 $L(d)$ 值为 86.61 , 随后集聚程 度不断减弱, 说明长江中游城市群创新平台总体区 位选择的空间范围为 $27.69 \mathrm{~km}$ 。就不同等级创新 平台而言, 国家级和省级创新平台的 $L(d)$ 曲线处于 上包络线之上, 同样表现出先增后降的倒“ $U$ ”型显 著集聚特征,空间集聚尺度的峰值及其对应的空间
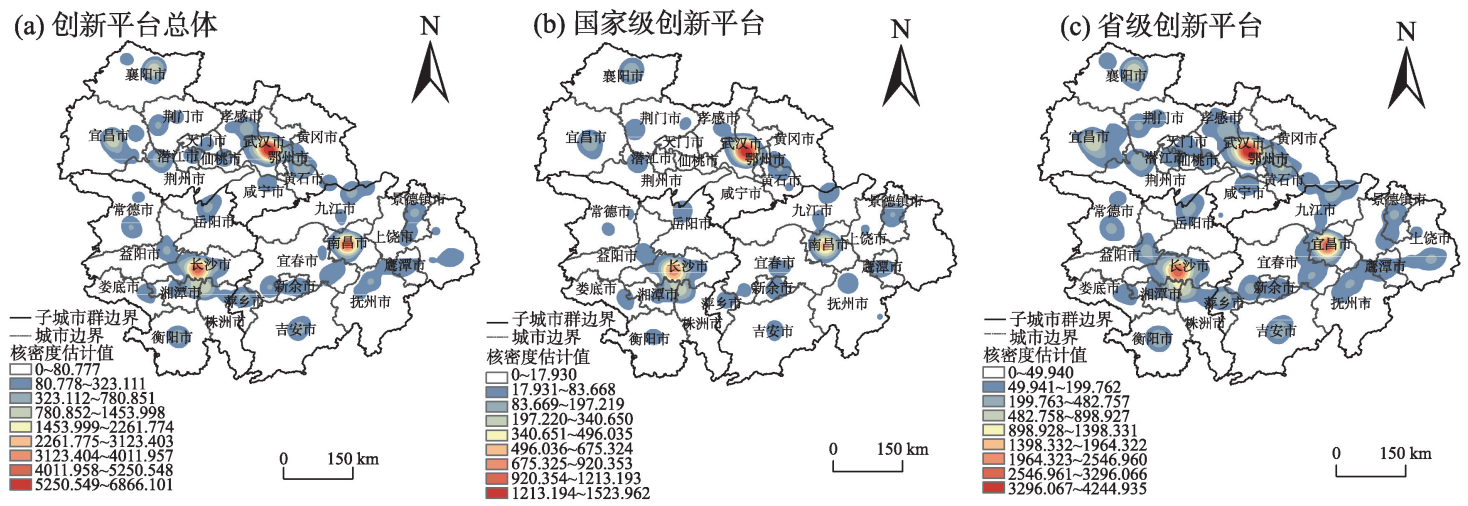

(d) 知识型创新平台

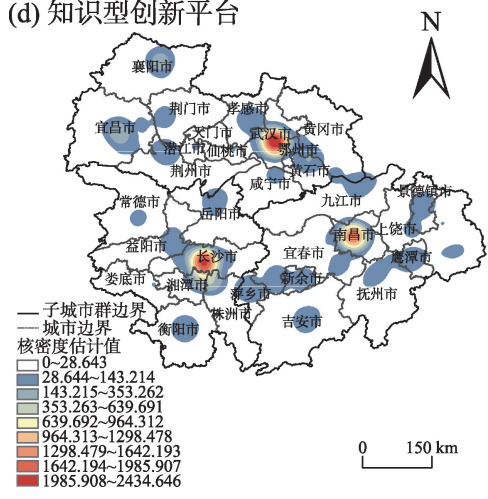

(e) 产业型创新平台
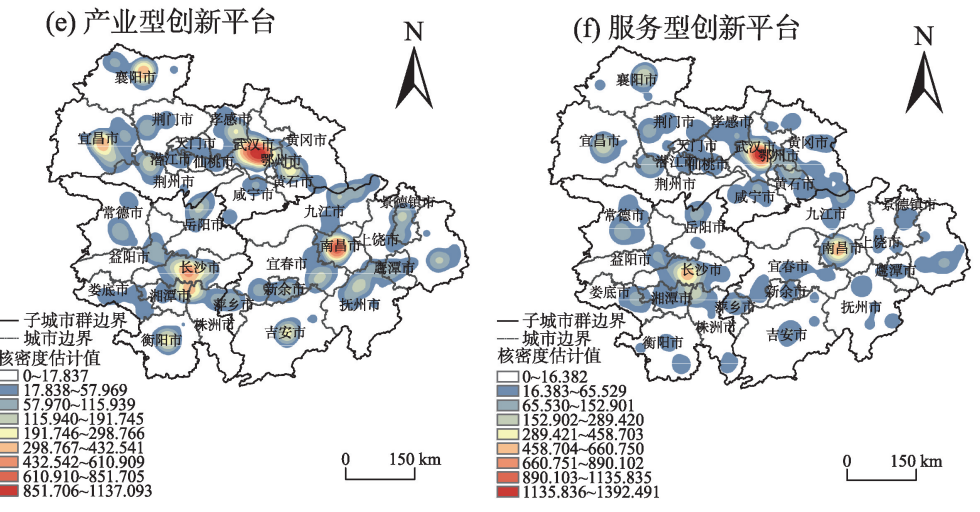

图 2 长江中游城市群创新平台核密度分析

Fig.2 Results of kernel density analysis of innovation platforms in urban agglomerations of the middle reaches of the Yangtze River Basin

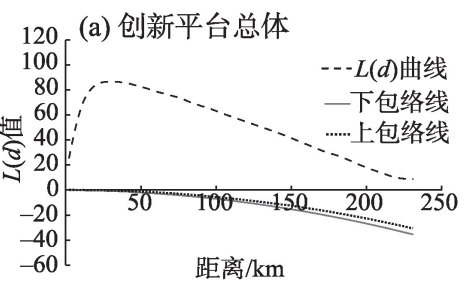

(d) 知识型创新平台

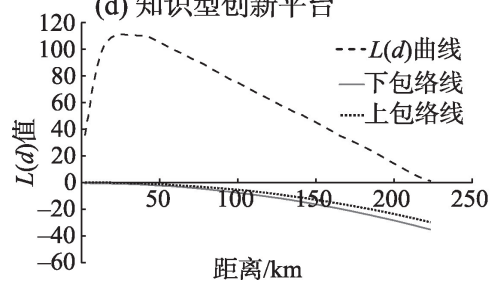

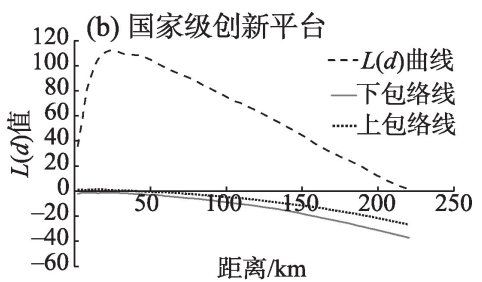

(e) 产业型创新平台

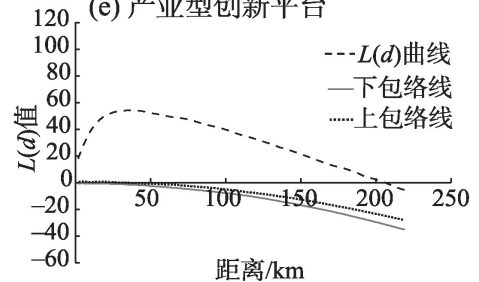

(c) 省级创新平台
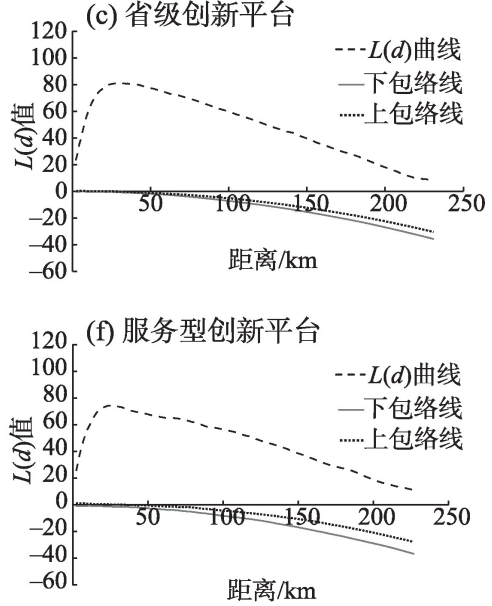

图 3 长江中游城市群创新平台 Ripley's $K$ 函数分析

Fig.3 Ripley's $K$ function of innovation platforms in urban agglomerations of the middle reaches of the Yangtze River Basin 
距离不同, 国家级和省级创新平台的 $L(d)$ 峰值分别 为 112.0563 和 80.8623 , 相对应的空间距离为 24.23 $\mathrm{km}$ 和 $32.31 \mathrm{~km}$, 说明由于受到数量、属性等因素的 制约, 国家级创新平台区位选择的空间范围比省级 创新平台小。就不同功能类别创新平台而言, 知识 型、产业型和服务型创新平台均通过显著性检验, 呈现出先增后降的倒“U”型显著集聚特征, $L(d)$ 达到 峰值的距离分别为 $26.78 \mathrm{~km} 、 35.03 \mathrm{~km}$ 和 $24.95 \mathrm{~km}$, $L(d)$ 峰值分别为 $111.49 、 54.39$ 和 74.39, 区位选择空 间范围由大到小依次为产业型创新平台、知识型创 新平台和服务型创新平台, 这是因为企业在地域分 布上比高校、科研机构等更加灵活, 服务型创新平 台作为目前还处在发展阶段的新兴平台且制约于 服务对象,其区位选择的空间范围为三者最低。

\section{3 长江中游城市群创新平台空间分布 的影响因素}

创新平台是区域创新活动的重要空间载体, 创 新活动的影响因素主要包括经济发展水平、人力资 本、创新环境、创新政策等, 结合目前已有的研究经 验 ${ }^{[11,13,23-25]}$, 遵循科学性、客观性和数据的可得性等原 则, 侧重人均与比重指标, 本文从城市经济发展水 平、对外开放程度、科技创新环境、社会公共环境等 4 个维度, 构建由 12 个指标组成创新平台空间分布 差异影响因素分析的指标体系(表3), 采用2017年 的相关统计数据进行影响因素的测度与分析。

\section{1 因子探测}

运用地理探测器中的因子探测计算各影响因 素对长江中游城市群创新平台空间分异的决定力 $q$ 值, $q$ 值越大说明该因素的影响越显著,结果见表 3 。 根据各因子决定力 $q$ 值的大小可知, 金融实力 $\left(X_{3}\right)$ 、 信息化程度 $\left(X_{11}\right)$ 、利用外资水平 $\left(X_{5}\right)$ 和人力资本条件 $\left(X_{6}\right)$ 对于创新平台的空间分异影响最为显著, 决定 力均在 0.7 以上; 其次包括交通可达性 $\left(X_{4}\right)$ 、城镇化 水平 $\left(X_{10}\right)$ 、经济基础 $\left(X_{1}\right)$ 和创新氛围 $\left(X_{9}\right), q$ 值位于 $0.4 \sim 0.7$ 之间; 而创新投人 $\left(X_{7}\right)$ 、绿色资源禀赋 $\left(X_{12}\right)$ 、 产业结构 $\left(X_{2}\right)$ 和科技进步 $\left(X_{8}\right)$ 的 $q$ 值低于 0.3 且未能 通过 0.05 的显著性检验, 对长江中游城市群创新平 台空间分异的影响较小, 因此对长江中游城市群创 新平台空间分异起主导作用的影响因素主要为金 融实力、信息化程度、利用外资水平、人力资本条 件、交通可达性、城镇化水平、经济基础和创新氛 围。结合各主导因素的决定力大小和分级图(图 4) 进行进一步分析, 金融实力的决定力为 0.8944 , 位 于所有因子之首, 金融资本富集意味着宽松的融资 环境, 便于创新平台融资, 有效解决资金难题, 获取 投资以及更多的资源, 保证创新活动的顺利开展; 信息化程度决定力为 0.8921 ,高度信息化有利于创 新平台获取政策等相关信息,实现资源共享,提高 产品质量, 提升工作效率, 及时掌握市场动态, 为创 新平台的发展提供相应的条件;利用外资水平的决 定力为 0.8908 , 对外开放是新知识传播和溢出的重 要手段,对外经济贸易对于创新平台的集聚具有较

表 3 长江中游城市群创新平台因子探测结果

Tab.3 Results of factor detection of innovation platforms in urban agglomerations of the middle reaches of the Yangtze River Basin

\begin{tabular}{|c|c|c|c|}
\hline 维度 & 指标名称 & 指标描述 & $q$ 值 \\
\hline \multirow[t]{3}{*}{ 城市经济发展水平 } & $X_{1}$ 经济基础 & 人均 GDP & $0.5638^{*}$ \\
\hline & $X_{2}$ 产业结构 & 第二、三产业产值占 GDP 比重 & 0.1793 \\
\hline & $X_{3}$ 金融实力 & 金融机构贷款余额占 GDP 比重 & $0.8944^{*}$ \\
\hline \multirow[t]{2}{*}{ 城市对外开放程度 } & $X_{4}$ 交通可达性 & 交通情况赋值 & $0.6665^{*}$ \\
\hline & $X_{5}$ 利用外资水平 & 人均实际使用外资金额 & $0.8908^{*}$ \\
\hline \multirow[t]{3}{*}{ 城市科技创新环境 } & $X_{6}$ 人力资本条件 & 每万人拥有 $\mathrm{R} \& \mathrm{D}$ 人员数 & $0.7655^{*}$ \\
\hline & $X_{7}$ 创新投人 & R\&D 内部经费支出占 GDP 比重 & 0.2606 \\
\hline & $X_{8}$ 科技进步 & 高新技术产业增加值占 GDP 的比重 & 0.1069 \\
\hline \multirow[t]{4}{*}{ 城市社会公共环境 } & $X_{9}$ 创新氛围 & 每万人拥有专利申请数 & $0.4720^{*}$ \\
\hline & $X_{10}$ 城镇化水平 & 城镇化率 & $0.6247^{*}$ \\
\hline & $X_{11}$ 信息化程度 & 互联网普及率 & $0.8921^{*}$ \\
\hline & $X_{12}$ 绿色资源禀赋 & 人均绿地面积 & 0.2499 \\
\hline
\end{tabular}

注: *代表通过 0.05 的显著性检验; 交通可达性即为各市主要交通情况赋值的总和,赋值公式为 $5 \times$ 机场数 $+4 \times$ 过境高速铁路数 $+3 \times$ 过境普 通铁路数 $+2 \times$ 过境高速公路数 $+1 \times$ 过境国道数。 
(a) 经济基础

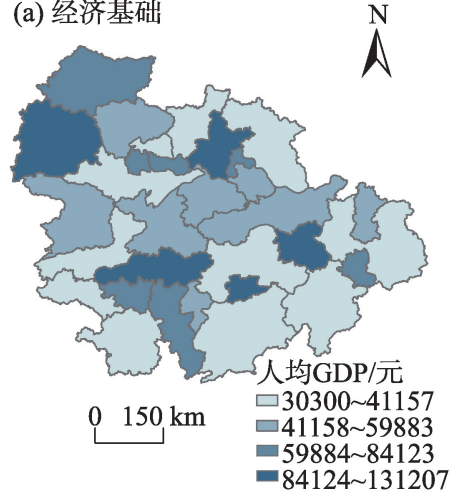

(d) 利用外资水平

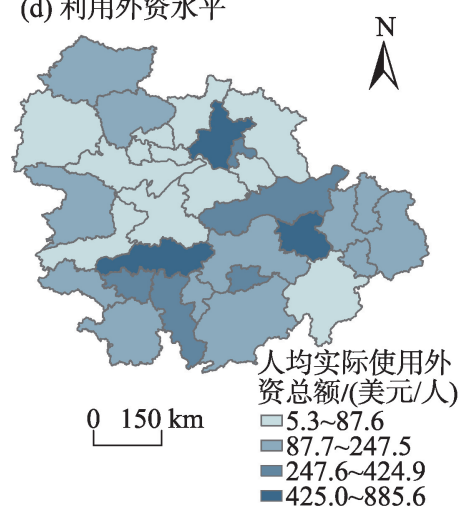

(b) 金融实力

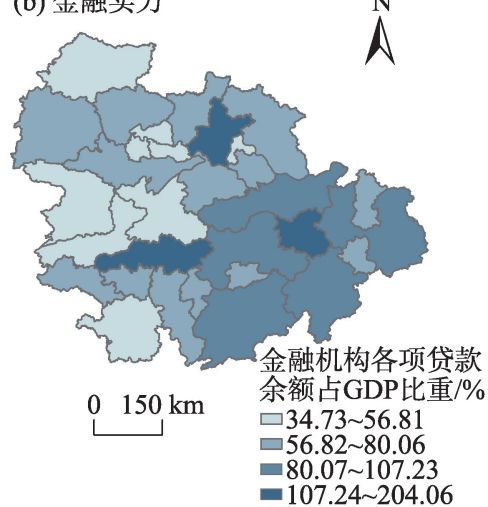

(e) 人力资本条件

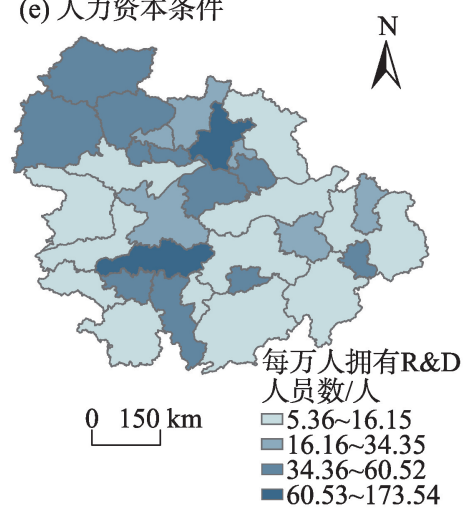

(c) 交通可达性

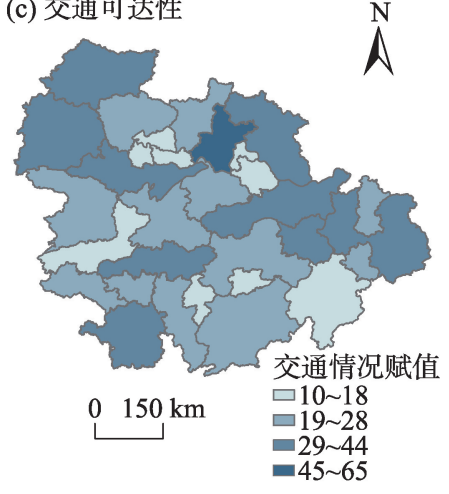

(f) 创新氛围

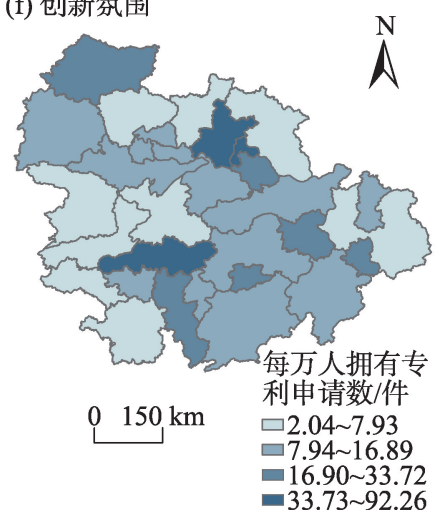

(g) 城镇化水平

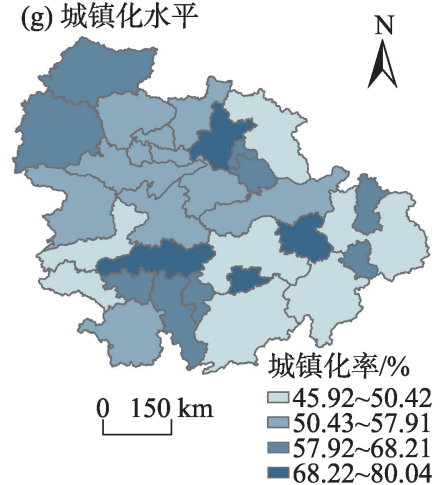

(h) 信息化程度

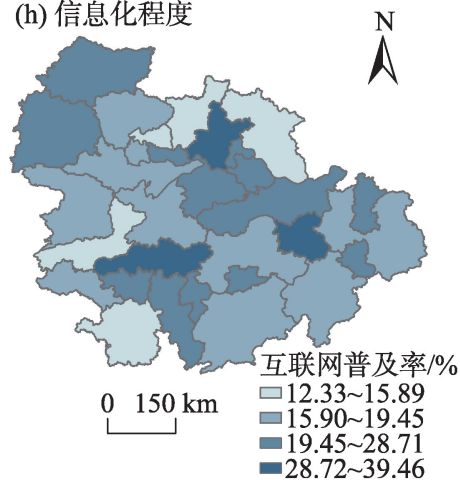

图 4 长江中游城市群创新平台主导因素分级

Fig.4 Classifications of leading factors of innovation platforms in urban agglomerations of the middle reaches of the Yangtze River Basin

强的推动力; 人力资本条件的决定力为 0.7655 , $R \& D$ 人员是开展科学研究与试验发展活动的基础, 其集聚有利于创新平台的发展和集聚; 交通可达性 的决定力为 0.6665 , 多样化的交通方式可以节约成 本, 提高生产生活的便捷性, 也有利于创新平台吸 纳、留住人才; 城镇化水平的决定力为 0.6247 , 城镇 化水平高, 供水、燃气、公共交通等基础设施建设较 为完善, 生活质量有一定的保障; 经济基础的决定 力为 0.5638 , 说明经济基础越好, 越容易进行创新 活动, 对于创新平台的需求就越大, 同样地, 创新平
台的建设促使新技术、新产品不断更新,产生新的 利润增长点, 经济得到发展; 每万人拥有专利申请 数反映了一个城市的创新氛围, 决定力为 0.4720 , 专 利申请数越多, 说明城市的创新氛围越好, 越有利 于创新平台的发展与集聚。

\section{2 交互探测}

运用地理探测器中的交互作用探测探究 2 个因 素共同影响创新平台空间分异时的作用程度, 交互 作用探测的结果见表 4 和表 5 。就交互因子的决定 力 $q$ 值而言, 影响因素与其他因素两两交互作用的 
表 4 长江中游城市群创新平台交互作用探测结果

Tab.4 Results of interaction detection of innovation platforms in urban agglomerations of the middle reaches of the Yangtze River Basin

\begin{tabular}{|c|c|c|c|c|c|c|c|c|c|c|c|c|}
\hline 因素 & $X_{1}$ & $X_{2}$ & $X_{3}$ & $X_{4}$ & $X_{5}$ & $X_{6}$ & $X_{7}$ & $X_{8}$ & $X_{9}$ & $X_{10}$ & $X_{11}$ & $X_{12}$ \\
\hline$X_{1}$ & 0.5638 & & & & & & & & & & & \\
\hline$X_{2}$ & 0.6510 & 0.1793 & & & & & & & & & & \\
\hline$X_{3}$ & 0.9041 & 0.9030 & 0.8944 & & & & & & & & & \\
\hline$X_{4}$ & 0.9083 & 0.8379 & 0.9731 & 0.6665 & & & & & & & & \\
\hline$X_{5}$ & 0.9189 & 0.9006 & 0.9099 & 0.9734 & 0.8908 & & & & & & & \\
\hline$X_{6}$ & 0.9362 & 0.8414 & 0.9347 & 0.9875 & 0.9320 & 0.7655 & & & & & & \\
\hline$X_{7}$ & 0.8922 & 0.3620 & 0.9762 & 0.8043 & 0.9775 & 0.8761 & 0.2606 & & & & & \\
\hline$X_{8}$ & 0.8830 & 0.6659 & 0.9698 & 0.8558 & 0.9720 & 0.8256 & 0.7146 & 0.1069 & & & & \\
\hline$X_{9}$ & 0.8540 & 0.7984 & 0.9462 & 0.9223 & 0.9326 & 0.9343 & 0.8850 & 0.5082 & 0.4720 & & & \\
\hline$X_{10}$ & 0.6533 & 0.6430 & 0.9056 & 0.9845 & 0.9085 & 0.9478 & 0.8756 & 0.8705 & 0.8442 & 0.6247 & & \\
\hline$X_{11}$ & 0.9050 & 0.9009 & 0.8995 & 0.9760 & 0.8962 & 0.9349 & 0.9701 & 0.9658 & 0.9345 & 0.9024 & 0.8921 & \\
\hline $\mathrm{X}_{12}$ & 0.5903 & 0.4887 & 0.9159 & 0.9106 & 0.9030 & 0.9713 & 0.7149 & 0.7300 & 0.7163 & 0.6557 & 0.9093 & 0.2499 \\
\hline
\end{tabular}

表 5 长江中游城市群创新平台交互作用关系

Tab.5 Interaction relationships of innovation platforms in urban agglomerations of the middle reaches of the Yangtze River Basin

\begin{tabular}{ll}
\hline \multicolumn{1}{c}{ 交互作用类型 } & \multicolumn{1}{c}{ 因素 } \\
\hline 非线性减弱 & - \\
单因子非线性减弱 & - \\
双因子增强 & $X_{1} \cap X_{2} 、 X_{1} \cap X_{3} 、 X_{1} \cap X_{4} 、 X_{1} \cap X_{5} 、 X_{1} \cap X_{6} 、 X_{1} \cap X_{9} 、 X_{1} \cap X_{10} 、 X_{1} \cap X_{11} 、 X_{1} \cap X_{12} 、 X_{2} \cap X_{3} 、 X_{2} \cap X_{4} 、 X_{2} \cap X_{5} 、 X_{2} \cap X_{6} 、 X_{2} \cap X_{7} 、 X_{2} \cap X_{10} 、 X_{2} \cap X_{11} 、$ \\
& $X_{3} \cap X_{4} 、 X_{3} \cap X_{5} 、 X_{3} \cap X_{6} 、 X_{3} \cap X_{7} 、 X_{3} \cap X_{8} 、 X_{3} \cap X_{9} 、 X_{3} \cap X_{10} 、 X_{3} \cap X_{11} 、 X_{3} \cap X_{12} 、 X_{4} \cap X_{5} 、 X_{4} \cap X_{6} 、 X_{4} \cap X_{7} 、 X_{4} \cap X_{9} 、 X_{4} \cap X_{10} 、 X_{4} \cap X_{11} 、 X_{4} \cap X_{12} 、$ \\
& $X_{5} \cap X_{6} 、 X_{5} \cap X_{7} 、 X_{5} \cap X_{8} 、 X_{5} \cap X_{9} 、 X_{5} \cap X_{10} 、 X_{5} \cap X_{11} 、 X_{5} \cap X_{12} 、 X_{6} \cap X_{7} 、 X_{6} \cap X_{8} 、 X_{6} \cap X_{9} 、 X_{6} \cap X_{10} 、 X_{6} \cap X_{11} 、 X_{6} \cap X_{12} 、 X_{7} \cap X_{10} 、 X_{7} \cap X_{11} 、 X_{8} \cap X_{9} 、$ \\
& $X_{8} \cap X_{11} 、 X_{9} \cap X_{10} 、 X_{9} \cap X_{11} 、 X_{9} \cap X_{12} 、 X_{10} \cap X_{11} 、 X_{10} \cap X_{12} 、 X_{11} \cap X_{12}$ \\
独立 & - \\
非线性增强 & $X_{1} \cap X_{7} 、 X_{1} \cap X_{8} 、 X_{2} \cap X_{8} 、 X_{2} \cap X_{9} 、 X_{2} \cap X_{12} 、 X_{4} \cap X_{8} 、 X_{7} \cap X_{8} 、 X_{7} \cap X_{9} 、 X_{7} \cap X_{12} 、 X_{8} \cap X_{10} 、 X_{8} \cap X_{12}$ \\
\hline
\end{tabular}

决定力均大于该因素单独作用的决定力, 交通可达 性与人力资本条件的交互作用对长江中游城市群 创新平台的空间分异影响最为显著, 其决定力 $q$ 值 为所有交互因子中最高, 达 0.9875 ; 产业结构与创 新投人交互作用的决定力 $q$ 值最低, 为 0.3620 。就 交互因子的作用类型而言,各影响因素之间的交互 作用类型有双因子增强型和非线性增强型 2 种, 不 存在相互独立、非线性减弱、单因子非线性减弱的 因素; 金融实力 $\left(X_{3}\right)$ 、利用外资水平 $\left(X_{5}\right)$ 、人力资本条 件 $\left(X_{6}\right)$ 、信息化程度 $\left(X_{11}\right)$ 与除自身外的其他 11 项因 素交互作用于长江中游城市群创新平台空间分布 时,均只产生双因子增强效应; 66 组交互因子中仅 有 11 组呈现出非线性增强效应, 有 55 组呈现出双 因子增强效应, 双因子增强型交互因子的比重为 $83.33 \%$, 说明绝大多数交互因子之间是交互协同作 用, 长江中游城市群创新平台的空间分异格局并不 是单因素造成的,而是多种因素综合作用的结果。

\section{4 结论与讨论}

以长江中游城市群 31 个城市为研究单元, 在现 有相关研究的基础上, 综合运用最邻近指数、核密 度估计、Ripley's $K$ 函数、地理探测器等方法探究了 长江中游城市群创新平台空间分布特征及其影响 因素,将创新平台总体和各类创新平台进行比较研 究,结合单因素和双因素交互作用综合分析影响因 素的作用强度且在一定程度上弥补了现有研究尺 度的不足,主要研究结论如下: (1) 长江中游城市群 创新平台总体空间分布不均衡, 呈现以武汉、长沙 和南昌为核心的“品字形”集聚特征,城市之间平台 数量差异显著,多集中在武汉、长沙、南昌、宜昌、襄 阳和株洲等城市, 天门、潜江、仙桃、鄂州等市分布 较少。(2) 基于不同级别和功能类别划分的长江中 游城市群各类创新平台均呈现显著集聚的特征,集 聚强度各一, 集聚区域差异显著, 但均属“点一极” 
布局模式, 虽然可以利用极化效应和扩散效应带动 整个城市群各类创新平台的发展, 但也容易造成集 聚不经济、产业链不完善等问题。(3)长江中游城市 群创新平台总体及不同类型创新平台的空间集聚 存在尺度效应, 空间集聚趋势随着地理距离的增加 均呈现出先增强后减弱的倒“U”型结构, 但区位选 择空间的范围受平台数量及属性、主要功能、依托 主体等影响存在差异。(4)长江中游城市群创新平 台的空间分异格局是多种因素综合作用的结果。 就单因素影响来看,金融实力、信息化程度、利用外 资水平、人力资本条件的影响最为显著, 其次为交 通可达性、城镇化水平、经济基础和创新氛围。就 双因素影响来看, 交互作用类型包括双因子增强和 非线性增强 2 种, 2 种因素交互作用比单因素作用 于创新平台空间分异时决定力更为显著。

本文初步揭示了长江中游城市群创新平台的 空间分布特征及其影响因素, 结合长江中游城市群 实际情况, 为构建城市群创新平台体系, 推动创新 活动发展提出若干建议: (1) 充分发挥增长极的核心 作用。武汉、长沙和南昌作为现阶段创新平台显著 集聚的区域, 应当利用自身优势, 将技术、人才、信 息等创新资源和创新活动扩散到周边城市, 从而带 动整个城市群创新平台的建设与发展。(2)优化创 新平台空间布局模式。3个子城市群应当淡化行政 区划范围, 依托沿江、沪昆和京广、京九、二广“两横 三纵” 等重点发展轴线, 促进城市群创新平台网络 化发展。(3) 构建多元创新平台体系。在尊重区域 科技发展规律的基础之上, 搭建以知识型创新平台 为核心、产业型创新平台为主体、服务型创新平台 为支撑的创新平台体系, 确保基础研究、产业化和 创新创业相关服务三者的顺利展开。(4) 为平台建 设与发展创造相应条件。各城市结合自身主导产 业和优势条件, 创造良好的融资环境, 推进 “互联 网+创业创新”, 促进对外贸易高质量稳定发展, 培 养和吸收科研人才。由于数据获取的原因, 本文仅 采用了创新平台的位置数据, 平台人员及科研产出 等具体指标并未涉及; 仅选取 2017 年数据分析创新 平台的空间格局, 未添加时段数据, 未能反映创新 平台的空间演变规律, 这些都将在后续相关专题中 展开研究。

\section{参考文献(References)}

[1] 孙庆, 王宏起. 地方科技创新平台体系及运行机制研究 [J]. 中国科技论坛, 2010(3): 18-21. [Sun Qing, Wang
Hongqi. Research on the system framework and operating mechanism of local sci-tech innovative platform. Forum on Science and Technology in China, 2010(3): 18-21. ]

[2] 周灿, 曾刚, 曹贤忠. 中国城市创新网络结构与创新能力 研究 [J]. 地理研究, 2017, 36(7): 1297-1308. [Zhou Can, Zeng Gang, Cao Xianzhong. Chinese inter- city innovation networks structure and city innovation capability. Geographical Research, 2017, 36(7): 1297-1308. ]

[3] Harmaakorpi V. Regional Development Platform Method (RDPM) as a tool for regional innovation policy [J]. European Planning Studies, 2006, 14(8): 1085-1104.

[4] 王雪原, 王宏起, 李文奇. 创新平台的识别与等级认定 [J]. 科学学研究, 2011, 29(6): 924-929, 867. [Wang Xueyuan, Wang Hongqi, Li Wenqi. Identification and rank confirmation of innovation platform. Studies in Science of Science, 2011, 29(6): 924-929, 867. ]

[5] 陈志辉. 科技创新平台内涵特征与发展思考 [J]. 科技管 理研究, 2013, 33(17): 34-37. [Chen Zhihui. Research on connotation, characteristics and development of science and technology innovation infrastructure. Science and Technology Management Research, 2013, 33(17): 34-37. ]

[6] 王雪原, 王宏起, 李文奇. 基于网络演化过程的区域创新 平台运行模式探讨 [J]. 中国科技论坛, 2012(6): 24-29. [Wang Xueyuan, Wang Hongqi, Li Wenqi. Regional innovation platform operational model. Forum on Science and Technology in China, 2012(6): 24-29. ]

[7] Schenk E, Guittard C, Pénin J. Open or proprietary? Choosing the right crowdsourcing platform for innovation [J]. Technological Forecasting and Social Change, 2019, 144: 303-310.

[8] Hallonsten O, Heinze T. Institutional persistence through gradual organizational adaptation: Analysis of national laboratories in the USA and Germany $[\mathrm{J}]$. Science and Public Policy, 2012, 39(4): 450-463.

[9] 王斌, 谭清美. 产业创新平台评价指标体系及其权重设 置研究 [J]. 科学学与科学技术管理, 2013, 34(12): 6368. [Wang Bin, Tan Qingmei. Study on the evaluation index system of industrial innovation platform and its weight setting. Science of Science and Management of Science and Technology, 2013, 34(12): 63-68. ]

[10] Carroll G P, Srivastava S, Volini A S, et al. Measuring the effectiveness and impact of an open innovation platform [J]. Drug Discovery Today, 2017, 22(5): 776-785.

[11] 孟国力, 吕拉昌, 黄茹. 北京 “众创空间” 区位选择特征 及影响因子分析 [J]. 首都经济贸易大学学报, 2016, 18 (5): 89-97. [Meng Guoli, Lv Lachang, Huang Ru. The characteristics of location selection and influencing factors of "Maker-Space" in Beijing. Journal of Capital Uni- 
versity of Economics and Business, 2016, 18(5): 89-97. ]

[12] 郭泉恩, 孙斌栋. 中国高技术产业创新空间分布及其影 响因素: 基于面板数据的空间计量分析 [J]. 地理科学 进展, 2016, 35(10): 1218-1227. [Guo Quan'en, Sun Bindong. Spatial distribution and influencing factors of hightech industry innovation in China: Based on spatial econometric analysis of panel data. Progress in Geography, 2016, 35(10): 1218-1227. ]

[13] 滕堂伟, 葛冬亚, 胡森林. 上海企业孵化器空间布局演 化及区位影响因子 [J]. 世界地理研究, 2018, 27(4): 118-126. [Teng Tangwei, Ge Dongya, Hu Senlin. Spatial distribution and location influencing factors of incubators in Shanghai. World Regional Studies, 2018, 27(4): 118-126.]

[14] Breheny M J, McQuaid R. The development of high technology industries: An international survey [M]. London, UK: Routledge, 2018.

[15] 孙庆, 王宏起. 区域科技创新平台网络化发展路径研究 [J]. 科技进步与对策, 2010, 27(17): 44-47. [Sun Qing, Wang Hongqi. Research on network development path of regional science and technology innovation platform. Science \& Technology Progress and Policy, 2010, 27(17): 44-47. ]

[16] 王晶, 甄峰. 城市众创空间的特征、机制及其空间规划 应对 [J]. 规划师, 2016, 32(9): 5-10. [Wang Jing, Zhen Feng. Spatial characters and planning strategy for mass innovation space. Planner, 2016, 32(9): 5-10. ]

[17] 段德忠, 杜德斌, 刘承良. 上海和北京城市创新空间结 构的时空演化模式 [J]. 地理学报, 2015, 70(12): 19111925. [Duan Dezhong, Du Debin, Liu Chengliang. Spatial-temporal evolution mode of urban innovation spatial structure: A case study of Shanghai and Beijing. Acta Geographica Sinica, 2015, 70(12): 1911-1925. ]

[18] 张永波, 张峰. 基于企业投资数据的京津冀科技创新空 间网络研究 [J]. 城市规划学刊, 2017(S2): 72-78. [Zhang Yongbo, Zhang Feng. A research on the spatial technological innovation network of Beijing-Tianjin-Hebei region based on the enterprise investment data. Urban Planning Journal, 2017(S2): 72-78. ]

[19] 鲜果, 曾刚, 曹贤忠. 中国城市间创新网络结构及其邻 近性机理 [J]. 世界地理研究, 2018, 27(5): 136-146. [Xian Guo, Zeng Gang, Cao Xianzhong. Structural feature and proximity mechanism of Chinese intercity innovation network. World Regional Studies, 2018, 27(5): 136-146. ]

[20] 李凌月, 张啸虎, 罗瀛. 基于创新产出的城市科技创新 空间演化特征分析: 以上海市为例 [J]. 城市发展研究, 2019, 26(6): 87-92, 33. [Li Lingyue, Zhang Xiaohu, Luo
Ying. Research on the evolution characteristics of innovation space from an output perspective: A case study of Shanghai. Urban Development Studies, 2019, 26(6): 8792, 33. ]

[21] 孙庆. 区域科技创新平台空间布局模式及其选择研究 [J]. 科技管理研究, 2012, 32(18): 36-39, 44. [Sun Qing. Research on spatial distribution modes and choose method of regional sci-tech innovation platform. Science and Technology Management Research, 2012, 32(18): 36-39, 44. ]

[22] 王雪原, 王宏起, 李文奇. 区域创新平台四维度布局优 化方法设计与实证研究 $[\mathrm{J}]$. 科学学与科学技术管理, 2012, 33(6): 100-106. [Wang Xueyuan, Wang Hongqi, Li Wenqi. Four- dimension distribution optimizing method design and positive research of regional innovation platform. Science of Science and Management of Science and Technology, 2012, 33(6): 100-106. ]

[23] 丛海涁, 邹德玲, 蒋天颖. 浙江省区域创新平台空间分 布特征及其影响因素 [J]. 经济地理, 2015, 35(1): 112118. [Cong Haibin, Zou Deling, Jiang Tianying. The spatial distribution and elements of regional innovation platforms in Zhejiang Province. Economic Geography, 2015, 35(1): 112-118. ]

[24] 滕堂伟, 覃柳婷, 胡森林. 长三角地区众创空间的地理 分布及影响机制 [J]. 地理科学, 2018, 38(8): 12661272. [Teng Tangwei, Qin Liuting, Hu Senlin. Spatial distribution and influencing factors of national Mass Makerspaces in the Yangtze River Delta. Scientia Geographica Sinica, 2018, 38(8): 1266-1272. ]

[25] 唐凯, 翟国方, 何仲禹, 等. 南京市众创空间时空分布格 局及演化机制研究 [J]. 现代城市研究, 2019(4): 52-59. [Tang Kai, Zhai Guofang, He Zhongyu, et al. The study on the spatio-temporal distribution patterns and evolution mechanism of makerspaces in Nanjing. Modern Urban Research, 2019(4): 52-59. ]

[26] 唐承丽, 吴佳敏, 贺艳华, 等. 城市群一开发区一产业集群 互动研究的理论思考 [J]. 地理科学, 2018, 38(1): 4957. [Tang Chengli, Wu Jiamin, He Yanhua, et al. Theoretical thinking on the interaction of urban-agglomeration development zone-industrial cluster. Scientia Geographica Sinica, 2018, 38(1): 49-57. ]

[27] 方创琳, 周成虎, 王振波. 长江经济带城市群可持续发 展战略问题与分级梯度发展重点 [J]. 地理科学进展, 2015, 34(11): 1398-1408. [Fang Chuanglin, Zhou Chenghu, Wang Zhenbo. Sustainable development strategy and priorities of spatially differentiated development of urban agglomerations along the Yangtze River Economic Belt. Progress in Geography, 2015, 34(11): 1398-1408. ]

[28] 肖刚, 杜德斌, 李恒, 等. 长江中游城市群城市创新差异 
的时空格局演变 [J]. 长江流域资源与环境, 2016, 25 (2): 199-207. [Xiao Gang, Du Debin, Li Heng, et al. The temporal and spatial evolution of city innovation differences in urban agglomeration in the middle reaches of the Yangtze River. Resources and Environment in the Yangtze Basin, 2016, 25(2): 199-207. ]

[29] 贾圭炎, 胡静, 刘大均, 等. 长江中游城市群 $\mathrm{A}$ 级旅游景 区空间演化及影响机理 [J]. 经济地理, 2019, 39(1): 198-206. [Jia Yaoyan, Hu Jing, Liu Dajun, et al. Spatial evolution and influence mechanism of A- level scenic spots in urban agglomeration in the middle reaches of the Yangtze River. Economic Geography, 2019, 39(1): 198206. ]

[30] 王劲峰, 廖一兰, 刘金金. 空间数据分析教程 [M]. 北京: 科学出版社, 2010. [Wang Jinfeng, Liao Yilan, Liu Xin. Analysis on spatial data. Beijing, China: Science Press, 2010.]

[31] 徐维祥, 张䈗娟, 刘程军. 长三角制造业企业空间分布
特征及其影响机制研究: 尺度效应与动态演进 [J]. 地 理研究, 2019, 38(5): 1236-1252. [Xu Weixiang, Zhang Yujuan, Liu Chengjun. Spatial distribution pattern and influencing factors of manufacturing enterprises in Yangtze River Delta: Scale effect and dynamic evolution. Geographical Research, 2019, 38(5): 1236-1252. ]

[32] Besag J E. Comments on Ripley's paper [J]. Journal of the Royal Statistical Society, Series B, 1977, 39: 193-195.

[33] 王劲峰, 徐成东. 地理探测器: 原理与展望 [J]. 地理学 报, 2017, 72(1): 116-134. [Wang Jinfeng, Xu Chengdong. Geodetector: Principle and prospect. Acta Geographica Sinica, 2017, 72(1): 116-134. ]

[34] 古志文. 群落生态学视角下的产业技术创新平台建设 与发展 [J]. 科技管理研究, 2016, 36(17): 117-122. [Gu Zhiwen. Construction and development of industrial technological innovation platform from the perspective of community ecology approach. Science and Technology Management Research, 2016, 36(17): 117-122. ]

\title{
Spatial distribution and influencing factors of innovation platforms in urban agglomerations of the middle reaches of the Yangtze River Basin
}

\author{
TANG Chengli', GUO Xiashuang ${ }^{1}$, ZHOU Guohua $^{1,2}$, WU Jiamin ${ }^{1}$, CHEN Weiyang ${ }^{1}$ \\ (1. College of Resource and Environment Science, Hunan Normal University, Changsha 410081, China; \\ 2. Hunan Provincial Key Laboratory of Geospatial Big Data Mining and Application, \\ Hunan Normal University, Changsha 410081, China)
}

\begin{abstract}
Innovation is the primary driving force behind development. As an important part of the regional innovation system and the core supporting carrier for the accumulation of innovative resources, innovation platforms are the main way to promote innovation-driven development. This study took the urban agglomerations of the middle reaches of the Yangtze River Basin as the research area and used the nearest neighbor index, kernel density estimation, Ripley's $K$ function, and geo-detector to explore the spatial distribution characteristics and influencing factors of the innovation platforms above provincial level in the urban agglomerations in 2017. The results show that: 1) The overall spatial distribution of the innovation platforms in the urban agglomerations is clustered, showing a triangular distribution pattern with Wuhan, Changsha, and Nanchang as the cores. 2) Innovation platforms of various scales and functional types exhibit significant agglomeration characteristics, but there exist certain differences in agglomeration intensity and state among them. 3) The overall innovation platforms and various types of innovation platforms show scale effect, which first strengthens and then weakens with the change of geographical distance. 4) The spatial differentiation of the innovation platforms is the result of multiple factors. Strength of financial resources, degree of informationalization, level of foreign investment, and conditions of human capital are most significant, followed by traffic accessibility, urbanization level, economic base, and innovation atmosphere.
\end{abstract}

Keywords: innovation platforms; spatial distribution; urban agglomerations of the middle reaches of the Yangtze River Basin 